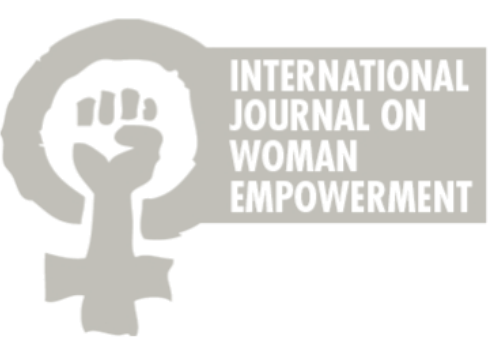

\section{Check for updates}

Copyright (c) The Author(s). 2021

This is an open access article distributed under the terms of the Creative Commons Attribution 4.0 International License, which permits unrestricted use, distribution, and reproduction in any medium, provided the original author and source are credited.

\section{(c) (1)}

DOI: 10.29052/2413-4252.v7.i1.2021.47-59

Citation: Asif M. Gender stereotypes in the Single National Curriculum, Pakistan. IJWE. 2021; 7(1): 47-59

\section{Corresponding Author Email:}

Myraelysium321@gmail.com

Funding: The author(s) received no specific funding for this work.

Conflicts of Interests: The author has declared that no competing interests exist.

Received 08/06/2020

Accepted 04/01/2021

First Published 13/11/2021

\title{
Gender stereotypes in the Single National Curriculum, Pakistan.
}

\section{Maira Asif}

University of Management and Technology, Lahore-Pakistan.

\section{Abstract}

Background: The Single National Curriculum (SNC) sponsored by the Government of Pakistan aimed to provide a level socio-economic playing field for all students. This paper analyzes the books of grades 1-5 under SNC to specifically test the gender biases and stereotypes promoted within them.

Methodology: The paper conducts a detailed inquiry of the various instances of overt and covert misogyny encountered in the text and illustrations of these books through the theoretical framework of the hidden curriculum. It looks at what kind of professional and personal activities men and women are depicted to be engaged in. By tallying all gendered illustrations and using qualitative content analysis to assess gendered textual biases, the research questions whether the state is promoting a certain gender ideology through these revised books.

Results: Several problematic depictions of women and the erasure of gendered minorities are revealed, and questions are raised about the purpose of such discrimination in a state-sponsored curriculum. Women are presented in stereotypical caregiving and similar roles in both public and private spaces, with meager representations in sports, STEM, and other professions. The texts also feature heavy religious sub-texts to lend the content credibility. Since the SNC is created and promoted by the state itself, the overt and covert misogyny in the textbooks exposes the state's endorsement of unequal gender norms in the country.

Conclusion: The SNC textbooks are actively promoting the hidden curriculum of gender inequality which will affect the behaviors and beliefs of the next generation. For the playing fields to be leveled for all, the books should have been gender-sensitive and should have actively reduced gender inequalities through their content. Alas, there are great discrepancies in the vision and the actual reality of the Single National Curriculum.

\section{Keywords}

Single National Curriculum Pakistan, Gender Bias in Education, Gender Equality Pakistan, Education Reform Pakistan. 


\section{Introduction}

According to Durrani', education is used to promote national identities and has the potential to strengthen the privilege of some groups in society, such as men's dominance over women. It reproduces, forms, defines, strengthens, and promotes gender norms and inequities.

Durrani ${ }^{1}$, UNESCO ${ }^{2}$, and Ullah et al. ${ }^{3}$ conducted an analysis of gender representations in the pre-2007 and post-2007 revised curriculums, respectively. Despite the revision of the curriculum in 2007, Ullah et al. $^{3}$ found their findings in line with those of UNESCO $^{2}$ and Durrani'. Across the textbooks, women were primarily shown in conventional gender roles, such as cooking, cleaning, washing clothing, raising children, and taking charge of household tasks. The patriarchal family unit is reinforced. Female representation in the workplace was restricted, with schoolteachers and physicians being the most common examples. Physical sports and exercise activities are attributed to men or male children. Thus, a clear, consistent pattern of marginalizing women in text exists and needs proper attention.

In his book on gender and textbooks, Kereszty ${ }^{4}$ states that textbooks represent what it means to be a child in a certain setting, which includes the socialization of gender identity. According to Peterson et al. ${ }^{5}$, one of the most primal and earliest learning experiences of a child is related to gender development. This development starts from the cradle and the home, but it is affirmed in the collective experiences of the school. In schools, children are exposed to both text and images in their curricula. The activities they end up doing are often in line with the expectations of the textbook. These books act as a channel for socialization into their cultures, ethical values, histories, and identities. They engage in social participation and start falling in line with the roles the books and the teachers instruct them to. Oftentimes, gendered roles are the first ones to be assigned. Using language and imagery (both illustrated and photographed), children develop their expectations of the masculine and the feminine ${ }^{6}$.
Peterson et al. found that multiple types of research contended a change in attitudes was caused by the consciousness of gender roles and identity stereotypes ${ }^{5}$. Children re-enacted the career aspirations of the characters they read about (also shown by Treichler et al ${ }^{7}$. They emphasize the adoption of sex-role stereotyping by children who read content laced with gender biases. Thus, gender differences in representation and prejudice in school textbooks require analysis and attention. These inequalities and differences have a lasting influence on children's life choices, motivations, self-esteem ${ }^{8}$, and identities. Hence, Textbook creators need to focus on content creation which dismantles harmful gender stereotyping. The way we teach our children will decide the future they will shape.

This paper thus builds on these arguments to inspect the gender-based differences in the recently inaugurated Single National Curriculum by the Government of Pakistan in 2020.

\section{What is the Single National Curriculum?}

"One system of Education for all, in terms of curriculum, medium of instruction and a common platform of assessment so that all children have a fair and equal opportunity to receive a high-quality education. The Single National Curriculum is a step in that direction" ${ }^{\prime \prime}$.

With topics and sub-themes such as peace and social cohesion, ideology, religious tolerance, respect, equity, and conflict resolution, the curriculum's primary premise is to instill ethical, social, and universal ideals in Pakistani learners. The SNC website claims that the goals of the curriculum are to promote the lessons of Quran and Sunnah, Quaid-e-Azam, to patch socio-economic disparity of opportunity between students, build national cohesion, and encourage critical problem-solving in the students ${ }^{9}$.

The National Curriculum Council took up the process of curriculum creation in 2018, and a task force was created with diverse stakeholders, including members of several NGOs, educational systems, and well-known experts in the sector. 
Various workgroups were created, including representatives from provincial and federal ministries, as well as educators from private schools. They are said to have evaluated existing materials on the issue, used research performed in bubbles in many fields, and provided a single curriculum that included all results ${ }^{10}$.

The new curriculum has gone into effect from March 2020. English, General Science, Mathematics, Social Studies, General Knowledge, and Urdu are the subjects due in grades 1-5. NonMuslim students have the option to choose Religious Education instead of Islamic Studies ${ }^{9}$.

The response to the SNC came on many fronts: from those praising the efforts to introduce a curriculum that will ensure "equality of opportunity" through a uniform curriculum to those wary of the Islamization of the content to those praising the Islamization of content to those questioning the constitutional jurisdiction of the federal government in imposing this curriculum on provinces to those regarding it as a panacea for socio-economic problems of the country ${ }^{11}$. This paper will focus on the representation of women and gendered minorities in the SNC books of grades $1-5$.

This paper aims to understand what gender ideology the state of Pakistan is sponsoring through its newly introduced unified curriculum. It analyzes gender roles in both text and illustrations through qualitative content analysis to accomplish this. The research hypothesizes the existence of gender biases and stereotypes in the SNC textbooks and thus questions:

1. How does the Single National Curriculum define ideal gender roles for Pakistani society?

2. What kind of professional and personal activities are men and women engaged in the Single National Curriculum?

3. Do the text and illustrations portray gender biases towards women and transgender persons?
Methodology

The books from Grade 1-5 under SNC first edition of 2020 were passed through qualitative content analysis. The analysis included counting all illustrations of men and women in the books in the first stage and then looking at the larger societal picture these numerical findings demonstrated through qualitative analysis ${ }^{12}$. No specialized statistical tools were employed in this process, and the framework of the Hidden Curriculum was used to aid the content analysis.

The clipart and the images were compounded into one tally of the overall gender categorization. In images with crowds of people, the maximum number added for people of any gender was 3 , and the minimum was 2. For clip arts that were of sizes 1 inch or less and displayed in the exercise portion of the books, the decision of omission was made. Images of historical figures such as Quaid-e-Azam or Begum Liaquat Ali Khan were not added into the tally of gendered images or illustrations. However, their frequency and context were noted and duly analyzed.

The textual content of the language books (Urdu and English) was studied for any gender stereotypes since these books convey social messaging through their text. The content of Social Studies, Islamic Studies, Science, and Math was analyzed for omissions, generalizations, and overt gender biases. Since the analysis and counting were done by one individual, an error in the tally of $+5 /-5$ and mistaken omission should be expected due to the physical and mental limitations of the researcher.

\section{Data collection}

The data is collected from the following books from Single National Curriculum 20209: English, Urdu, Social Studies, Maths, Gender Science, and Islamic Studies (Grades 1-5). 
Results

The following table describes all the male and female authors and designers/illustrators involved in the book-making process.

Table 1: Total personnel involved in textbook production (all subjects) for grades.

\begin{tabular}{lcccc}
\hline \multirow{2}{*}{ Subjects } & \multicolumn{2}{c}{ Author } & \multicolumn{2}{c}{ Designer/Illustrator } \\
\cline { 2 - 5 } & $\mathbf{M}$ & $\mathbf{F}$ & $\mathbf{M}$ & $\mathbf{F}$ \\
\hline English & 0 & 5 & 9 & 2 \\
\hline Urdu & 3 & 2 & 13 & 0 \\
\hline Social Study & 1 & 2 & 7 & 1 \\
\hline Gen Science & 2 & 0 & 2 & 1 \\
\hline Islamic Studies & 3 & 3 & 4 & 0 \\
\hline Math & 3 & 3 & 12 & 0 \\
\hline Total & 12 & 15 & 47 & 4 \\
\hline
\end{tabular}

Head Supervisor was Muhamad Rafique Tahir, Joint Educational Advisor, National Curriculum Council Ministry of Federal Education and Professional Training, Islamabad. Hence, the authority figure in charge of the curriculum was a man, as inferred from the masculine name.

The following table presents the overview of the collected data on the frequency of male/female illustrated characters in all the above books.

Table 2: Grade-wise distribution of male/female characters in textbooks of various subjects.

\begin{tabular}{|c|c|c|c|c|c|c|c|c|c|c|c|c|}
\hline \multirow[t]{2}{*}{ Grades } & \multicolumn{2}{|c|}{ Math } & \multicolumn{2}{|c|}{ Urdu } & \multicolumn{2}{|c|}{$\begin{array}{l}\text { Islamic } \\
\text { Studies }\end{array}$} & \multicolumn{2}{|c|}{$\begin{array}{l}\text { General } \\
\text { Science }\end{array}$} & \multicolumn{2}{|c|}{$\begin{array}{l}\text { Social } \\
\text { Studies }\end{array}$} & \multicolumn{2}{|c|}{ English } \\
\hline & $\mathbf{F}$ & $\mathbf{M}$ & $\mathbf{F}$ & $\mathbf{M}$ & $\mathbf{F}$ & $\mathbf{M}$ & $\mathbf{F}$ & $\mathbf{M}$ & $\mathbf{F}$ & $\mathbf{M}$ & $\mathbf{F}$ & $\mathbf{M}$ \\
\hline 1 & 48 & 99 & 54 & 94 & 0 & 0 & 0 & 0 & 90 & 74 & 78 & 106 \\
\hline 2 & 71 & 114 & 48 & 98 & 0 & 0 & 0 & 0 & 80 & 140 & 64 & 125 \\
\hline 3 & 80 & 130 & 45 & 119 & 0 & 0 & 0 & 0 & 41 & 87 & 85 & 153 \\
\hline 4 & 96 & 135 & 28 & 78 & 0 & 0 & 18 & 65 & 26 & 65 & 74 & 149 \\
\hline 5 & 80 & 122 & 28 & 44 & 0 & 0 & 8 & 12 & 23 & 47 & 72 & 133 \\
\hline Total & 375 & 600 & 203 & 433 & 0 & 0 & 26 & 77 & 260 & 413 & 373 & 666 \\
\hline
\end{tabular}

Table 3: Profession-wise distribution of male-female characters in textbooks.

\begin{tabular}{lcccccccccc} 
& Grade & \multicolumn{3}{c}{ Grade } & \multicolumn{3}{c}{ Grade } & \multicolumn{2}{c}{ Grade } & \multicolumn{2}{c}{ Grade } \\
\multicolumn{1}{c}{ Profession } & $\mathbf{1}$ & & $\mathbf{2}$ & & $\mathbf{3}$ & & $\mathbf{4}$ & & $\mathbf{5}$ \\
& $\mathbf{F}$ & $\mathbf{M}$ & $\mathbf{F}$ & $\mathbf{M}$ & $\mathbf{F}$ & $\mathbf{M}$ & $\mathbf{F}$ & $\mathbf{M}$ & $\mathbf{F}$ & $\mathbf{M}$ \\
\hline Doctor/Surgeon & 0 & 1 & 2 & 2 & 5 & 3 & 0 & 10 & 0 & 3 \\
\hline Nurse & 0 & 0 & 4 & 0 & 2 & 0 & 3 & 0 & 2 & 0 \\
\hline Teacher & 5 & 1 & 3 & 5 & 4 & 4 & 0 & 1 & 2 & 0 \\
\hline Skilled worker & 0 & 0 & 0 & 12 & 1 & 9 & 0 & 0 & 2 & 3 \\
\hline Unskilled worker & 0 & 3 & 4 & 11 & 0 & 12 & 5 & 6 & 0 & 6 \\
\hline Farmer/fisher & 0 & 1 & 4 & 16 & 1 & 5 & & 0 & 0 & 6 \\
\hline STEM professional & 0 & 0 & 0 & 0 & 0 & 0 & 3 & 2 & 2 & 2 \\
\hline $\begin{array}{l}\text { Other professions (Pilot, } \\
\text { chemist, banker, etc.) }\end{array}$ & 0 & 0 & 4 & 5 & 4 & 4 & 0 & 4 & 0 & 0 \\
\hline
\end{tabular}




\begin{tabular}{lccccccccccc}
$\begin{array}{l}\text { Other vocations (Driver, } \\
\text { delivery person, shopkeeper, } \\
\text { etc.) }\end{array}$ & 3 & 4 & 0 & 19 & 1 & 14 & 0 & 11 & 0 & 9 \\
\hline Police/army/politics & 0 & 1 & 0 & 8 & 0 & 6 & 0 & 26 & 1 & 2 \\
\hline Sports & 2 & 19 & 1 & 29 & 5 & 48 & 0 & 14 & 0 & 7 \\
\hline Total & 10 & 30 & 22 & 107 & 23 & 105 & 11 & 74 & 9 & 38 \\
\hline
\end{tabular}

\section{The Hidden Curriculum and Gender Dynamics}

The term "Hidden curriculum" was introduced by Philips Jackson in the 1970s and is attributed to the institutional patterns and rituals which mark the teacher-student relation ${ }^{13}$. In this paper, we will be using a modified Hidden Curriculum framework, which looks at the relationship between the students and the textbooks they use.

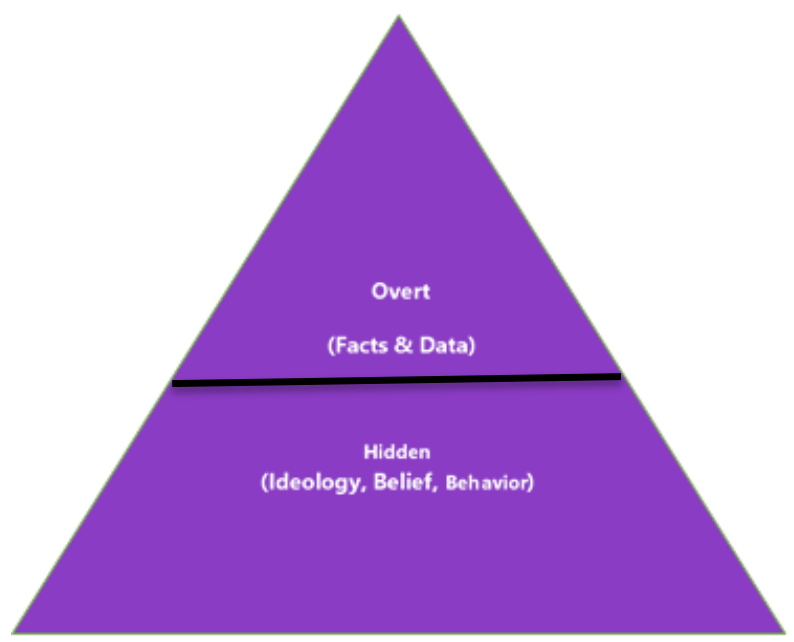

Modified Hidden Curriculum Conceptual Framework for Gender Bias in SNC

Redundancy of sexist sub-text + omission of counternarrative + romanticized Islamic gender norms for high emotional reward value

Assor et al. ${ }^{13}$, in their revisit of the hidden curriculum theory, clarify the following points:

1. The knowledge which the dominant authority wants the student to retain long-term is repeatedly presented through various means. This knowledge often stays with the student way longer than the rest of their learnings.

2. The knowledge taught through implicit learning is often normative beliefs, ideologies, and group conformity values for civic-economic life.

3. The knowledge which has a higher emotional reward point needs not to be repeated as often because it is easily understandable and acceptable. However, for the knowledge with lower emotional reward points, redundancy is the key to successful imprinting. Emotional reward points are linked to the internal cognitive structures of the student, meaning things that are socially, culturally, or personally relatable to the 'normal.'

4. The expected knowledge is often imprinted not just because of its redundancy or emotional value but because of the lack of alternative narratives to challenge it.

5. The knowledge that corresponds to the external environment of the student often goes unchallenged and gets deeply rooted in the student's mind. ${ }^{13}$ 
Statement 1, 2, and 4 falls in the purview of textbooks, while 3 and 5 involve social interactions among people instead. Since this research hypothesizes the existence of gender biases and stereotypes in the SNC textbooks, the former statements above can be interpreted as the following and serve as an extended hypothesis to be tested:

1. The implicit belief that the state wants to imprint on the student's mind is that of a maledominated, gender-biased status quo rooted in religious conservatism ${ }^{14}$.

2. The knowledge of status quo, male-dominated gender roles, and identities is thus repeated often in multiple ways because the dominant authority/the state wants the student to retain these gender norms through this statesponsored curriculum.

3. The consistent omission of counter-narratives (women in public spaces, in power, with choices, etc.) is the missing counter-narrative, which had to be present for the student to challenge the implicit messaging.

As Rubina Saigol succinctly puts it:

"The Pakistani state... was also creating ideological and internal frontiers against the others at home... thus engaged in constructing the 'good Muslim woman' as the opposite of the 'good Muslim

$$
\text { male }^{\prime \prime 14} \text {. (p.12) }
$$

\section{Finding Patriarchal, Religiously Conservative Gender Norms in SNC Textbooks}

\section{Gendered Minorities}

There was no presence of any transgender person in the books in any text or pictures.

\section{Hijab and Dress}

In Social Studies ${ }^{15}$, the images of women (both pictures and clip art illustrations) had a healthy balance of hijab and no hijab, with a tilt towards women in hijab. This is an accurate representation of Pakistan's society, where some women wear the hijab, and others don't. Pictures of women in full covering burqas were also sprinkled across the book.
In General Science ${ }^{16}$, the images in the grade 4 book were mostly of children dressed in shalwar kameez and young hijab-less girls. However, in grade 5 books, girls of all ages are wearing hijab. Interestingly, every time a "western" girl is depicted, she is not wearing a hijab. Hence, a clear 'us' v 'them' narrative is created through these images. 'Our' girls wear hijabs, 'their' girls don't. This can also be seen as cultural exposure and respect for differences of opinion.

\section{Sports}

In General Science ${ }^{16}$, only men and boys have been represented in sports activities as adults such as soccer or cricket. Girls only engage in leisurely playing in their childhood, never sports.

In grade 3 English ${ }^{17}$, the books take the gender role assignment up a notch, with a very clear statement in a chapter on Sports and Games: "Girls and boys run around to play the games they like. Girls enjoy swings more whereas boys love to go round and round the hanging tire." This limiting statement sets the ground for the separation of spaces for men and women in the minds of children. Girls play sophisticated non-sports, while boys play aggressive, athletic sports. This messaging is strengthened using illustrations that feature zero girls engaged in sports.

\section{Activities}

In the science books ${ }^{16}$, girls are mostly playing, and only some are actively participating in exploration and experimentation.

Mathematical ${ }^{18}$ books have the most representation of women in STEM, apart from Urdu. These women are usually represented as scientists wearing lab coats and working with chemistry equipment.

Grade 4 English $^{17}$ book repeats the following gender dynamics:

- Girls $\rightarrow$ Play with dolls, do their chores, helped mom and dad, good girl, reading, bought a dress, sewn a dress, playing outside with boys and girls as a child, staying indoors with girls as age increases. 
- $\quad$ Boys $\rightarrow$ Climb a tree, play cricket, naughty boys, helped mom at home, planting trees, outside the home playing, engaged in a vast variety of sports, playing with girls too as a child, playing only among boys as age increases.

\section{Illustration}

Both books on General Science ${ }^{16}$ used male bodies to teach children about the human body. From the silhouettes to the hands used, only male bodies were featured throughout the books.

Most of the representation of men was through pictures of real men in real-life activities, while the most representation of women was in the form of clipart or illustrations. Rare were any pictures of actual women in any subject's textbook throughout the curriculum ${ }^{9}$.

In social studies ${ }^{15}$, the historical women figures seemed to have worked primarily to empower women, while the narrative for male figures of saving the nation.

While in Urdu ${ }^{19}$, the poets featured were exclusively all males. The figures of history mentioned in the books were also all men, with the exception of Islamic women of note such as Hazrat Fatima, Hazrat Ayesha, and Hazrat Khadijah, etc.

\section{Interaction with the opposite sex}

The science ${ }^{16}$ books did not differentiate between activities performed by men and women. Children of both genders were shown to interact freely in school, homes, and playgrounds. They displayed curiosity for learning and performed experiments together or alone.

The social studies ${ }^{15}$ books showed: little girls and boys playing together in schools or playgrounds. little girls and boys learning lifestyle ethics together, teenage girls helping younger siblings, same-sex teenage classrooms, adult men working in a very diverse range of jobs outside the home, adult women absent from the scene, except rarely appearing as teachers or nurses or such, adult men and women as mother and father at home attending to their children
Children played together in english ${ }^{17}$ books from grade 1 to 3 but started playing and working in same-sex groups from grade 4 and 5 onwards. Similar trends can be seen sporadically in other subjects as well, but the transition of interaction behaviors was most prominent in English books.

\section{Textual representation}

In all SNC ${ }^{9}$ books, the text was gender-neutral and addressed the reader in a direct voice: "Imagine you are a superstar." The child reading the text could feel a personal attachment to the activities it was directing them to partake in or the knowledge it was imparting to them. This was also observed in all other books.

In Islamic studies ${ }^{20}$, multiple chapters on male Muslim personalities of note were given. But none of the women of value in Islamic history, except those who were married to notable men in the context of marriage mostly.

From English ${ }^{17}$ books of grade 1 to grade 5, the books went from covert misogyny to overt sexism.

One finds multiple references to concepts of 'good girl' being promoted, while boys were usually depicted as naughty in comparison.

"She is a good girl. He is a naughty boy." Grade 2: Page 9

"Sadia is a good girl. She obeys her parents. My brother is very naughty. He has many toys." Grade 2: Page 39

"Sara is a good girl" Grade 2: Page $74^{17}$

In English ${ }^{17}$ Grade 5 Chapter 'Women as role models' Pg. 26: "Our women have always been a great support for men. They are equal to men in terms of spirit, hard work, achievement, etc. Their positive qualities are helping us build a strong nation." The statement has very clearly demoted women from equality with men and put them in the secondary role.

Grade 5, page 90, fill-in-the-blank exercise: Brave men work while others sleep 
The men who dare while others cry Great men lift the nation to the sky Only men can make a nation strong

Islamic Studies ${ }^{20}$ Grade 3 Page 98 chapter on Hazrat Khadijah: "After their marriage, she endowed all the money, wealth and possessions she had onto the Prophet. She served him day and night and stood by him in all circumstances. She gave him useful advice."

Islamic Studies ${ }^{20}$ Grade 4 Chapter 16 Page 104 the text states that after her marriage, Hazrat Fatima is said to "do all the house chores by herself and remain content in all circumstances." This model of the uncomplaining, content woman is again validated by showing the ideal of women to be committing to it.

\section{Disability Representation}

All SNC ${ }^{9}$ books have multiple depictions of people with disabilities. However, only lower-body mobility-related disability was shown, which is the stereotypical image of what disability looks like. There is clearly room for improvement here. Disabilities are diverse, and children deserve to know that to support their peers.

\section{Clear Omissions}

Gender-specific issues were not addressed in Islamic Studies ${ }^{20}$. Except for one paragraph which stated: "Islam has given women the most rights out of all other religions. Muslim women have rights to inheritance, education, and so on..."

In social studies ${ }^{15}$, a clear attempt to address contemporary issues was made, such as cultural diversity and human rights. However, the issue of gender inequality is omitted. There was no mention of the gendered violence that takes place in Pakistan.

\section{Profession wise distribution}

In social studies ${ }^{15}$, while men were shown engaged in activities from fatherhood, house chores, sports, STEM, agriculture, management, politics, defense, labor, and more, women were represented only in conventional manners. We find only 2 female doctors, 1 sportswoman, and 2 pilots who strayed from conventional 'female' jobs. Women were mostly shown to be working as farmers, nurses, teachers, mothers, unskilled labor. However, even in these categories, more men were engaged in work than women.

Overall ${ }^{9}$, women were seen working in 75 instances while men were in 354. Among these instances, 41 were in conventional professions (Teacher, unskilled worker, nurse, etc.), 29 were in unconventional careers (STEM, Sports, Police), and 5 were as rural workers (Farmers).

11 women were nurses, and 7 were doctors, in contrast with 26 male doctors. 0 male nurses were shown. 25 women teachers were shown, while 11 men were depicted in this role. Only 9 women worked as unskilled workers in comparison to 38 men. Only 4 women held any blue color public jobs in comparison with 57 men. The police and armed forces had almost all men with 43 out of 44 . Out of the 125 images of people engaged in sports, only a measly 8 were of women. Only one positive trend existed for women were in STEM, 5 women and 4 men were portrayed ${ }^{9}$. This entire curriculum emphasizes gender stereotyping and re-iteration of traditional gender roles. The state clearly does not hold the will or desire for women's empowerment ${ }^{8}$. 


\section{Discussion}

The implicit belief that the state wants to imprint on the student's mind is that of a male-dominated, gender-biased status quo rooted in religious conservatism ${ }^{14}$.

The finding above shows that the state prefers the segregation of adult women and men in public spaces such as educational institutes and workplace choices. Women and men are acting out their status quo gender roles ${ }^{8}$ in both text and illustrations as seen by the proliferation of young hijab-adorned girls, absence of images of actual women from the books, women and men working in traditional jobs, etc.

The content in the books collectively creates this narrative: young children play and learn together, regardless of gender differences. With age, they separate into different schools and learning environments. Upon graduation from education or if unable to find an education, men or male teenage children engage in labor or skilled and unskilled jobs of all kinds. Women serve the community through teaching or attending to patients as doctors or working as nurses, or occasionally working as a pilot or cricketer, or office worker. But even though women are absent from the world at large, they are present at home with their husband and kids in a perfect family unit of 4 . They are kind mothers who are knitting or doing dishes, while fathers either read the paper or give life lessons to kids. UNESCO ${ }^{2}$ and Durrani ${ }^{1}$ found similar gendered life plan narratives in the older curricula. While the entire story is full of gendered tropes, the transition from a girl to a wife or a mother is too abrupt and deeply concerning. The lack of representation of working women creates a vacuum for this to happen. In a country where girls are married off too young too often, this narrative is dangerous to perpetuate ${ }^{21}$.

The knowledge of status quo, male-dominated gender roles, and identities is thus repeated often in multiple ways because the dominant authority/the state wants the student to retain these gender norms through this state-sponsored curriculum.
As seen in the data charts and in the findings above, the gender roles of men and women have been frequently repeated and reemphasized. The gender trope of 'good girl' is often repeated in the text, and the representations are given in the illustrations. A good girl is one who is obedient, quiet, submissive, and does well in everything she is told to do. A bad girl is an opposite: one who doesn't follow orders without questioning is loud, assertive, and true to herself. The former is acceptable and socially valued in a patriarchal system. Good girls tolerate naughty, good boys because that's what good girls do, and that's what good boys are. Good boys are supposed to be unruly, naughty, mischievous, and assertive. While the patriarchal bad (wrong) boy is the soft boy, the submissive boy, the obedient boy. These binary gender roles are deeply problematic and emblematic of the oppressive nature of patriarchy for all involved ${ }^{27,32}$.

Take the example of the autobiography of Hazrat Khadijah and Hazrat Fatima from the Urdu ${ }^{19}$ textbooks.

At the start of the book, Hazrat Khadijah is depicted as a trade tycoon. However, the chapter ends with this sentence on a clear change of her role as a woman and a business owner. The text states that she gave all her possessions to the Prophet PBUH and served him day and night. This unassuming wifely devotion is being depicted as her virtue. Since all women should emulate her as a role model, the children reading these words see it as a roadmap of what the ideal woman and wife looks like. The question arises if all other women should give up their careers and possessions to serve their husbands. Since the role model did so, per the text, then so should the followers. Even if there is no historical consensus on the status of her working after marriage ${ }^{22}$, it is problematic that the book chose to phrase the words ambiguously in favor of the status quo, which demands female subservience to her husband and paints it as the truest joys of her life. Since women are forced to give up their earnings, their inheritance, even their bodies to the whims of their husbands in Pakistan, it is dangerous to validate such practices. These 
books are written for the impressionable minds of children, and the state-supported books present very disturbing narratives for imitation ${ }^{3,4}$.

In the story of Hazrat Fatima in the Urdu ${ }^{19}$ books, the biography is quite an endearing story of fatherly love for a daughter, which is appreciable. However, the insistence that she did all chores by herself and lived intently in all situations reinforces the silent culture-making women's suffering invisible. What's worse is that it is untrue since it is reported in a Hadith that the Prophet PBUH and her husband Ali RA helped her with her childcare and housework whenever they could ${ }^{23}$. She was also reported to have felt overwhelmed at times and was taught the Tasbih Fatima by the Prophet $\mathrm{PBUH}^{24}$. But those non-content, struggling, imperfect moments were omitted in favor of the non-complaining perfect women archetype. Because of this culture of silence, women tend not to ask for help and bear pain on their own. This carries over in cases of abuse, violence, and even access to health care ${ }^{25}$.

Another example of note is the statement: "Women are great supporters of men," from the English ${ }^{17}$ book. Our women have always been a great support to men means women's existence only matters in relation to men. They provide support to men, and that support to the primary work of the male citizen makes them valuable. Hence, conditionality has been added to women's worth. A woman citizen is a valuable role model if and only if her work does not go in contrast with the primary needs and vision of the male citizen. This is clearly a problematic way to introduce women as role models to children.

The statement goes on to say, "Women are equal to men in spirit and hard work." This abstract equality is deceptive. To be equal in spirit is meaningless because it is simply an innate ethos. To be equal in hard work is also meaningless because even two people with vastly different circumstances will get vastly different results for equal hard work. Similarly, the structural inequalities of misogyny make it impossible for equal hard work to exist between men and women, let alone for that work to render any equal achievements realistically.

To better understand the insidiousness of this statement, let me rephrase the argument:

Equality is an unconditional, limitless phenomenon. Limited equality is inequality ${ }^{26}$. "Man is defined as a human being and woman as a female - whenever she behaves as a human being, she is said to imitate the male" 27 .

The consistent omission of counter-narratives (women in public spaces, in power, with choices, etc.) is the missing counternarrative, which had to be present for the student to challenge the implicit messaging.

Clear guidelines on how to treat religious minorities or even hateful comments online are given to children across the books. However, they were not even nudged in the direction of proper conduct with the opposite gender or made to understand the fundamentals of gender differences in the world. Such an omission paved the way for the extremely gendered representation of characters in the book. The omission is a clever deception where no discriminatory act has been committed outright, so if caught, a simple excuse of poor oversight or human error could be pleaded. Omission bias also shows the person or, in this case, the state ideology of the policymakers $^{28}$.

Even when female biographies were given, they were mere facts and bore little to no comparison with the detailed chapters on male figures. The lack of narrative depth to women's lives implies that the narrative was of no significance. These women just worked for other women without detailed political, historical, or philosophical ideologies or struggles. And that's all that is there to know about them. No image of women in defense forces such as the army or police seems to reiterate this point: Women work to empower women; men work to create a better world. Hence, the creation of a better world is a man's job; women should stay in their women's quarters ${ }^{26}$. 
The clever omissions of any discussion on gender inequality stand side by side with the gaslighting statement in Islamic Studies ${ }^{20}$ books: "Islam has given women the most rights out of all other religions." Thus, it is no longer omission but rather denial of ground realities of gendered oppression in Pakistan ${ }^{21,29}$.

Finally, the erasure of transgender people from the books adds to the ignorance that the larger society has about their community and rights. This ignorance will only exacerbate the abuse, violence, and ostracization they face. Such erasure is a human rights abuse in itself for a community at least half a million strong ${ }^{29}$.

\section{Impact of the Hidden Curriculum}

The hidden-curriculum notion is based on the idea that children acquire teachings in school that aren't necessarily part of the regular curriculum. The lessons of the official curriculum might be reinforced by a hidden curriculum, or it can be contradicted by a hidden curriculum. While most of the Single National Curriculum is not overtly misogynistic, a deeper analysis reveals the gender biases of the hidden curriculum. Assor et al ${ }^{13}$ state that the contents of the hidden curriculum might be retained longer when they resonate with the status quo (i.e., have a higher emotional reward point). Since Pakistan is a conservative country with prevalent sexism, the hidden curriculum is fortifying these regressive values and ways of life in the children. In some places, the curriculum itself gets overtly misogynistic, and thus the official curriculum and the hidden curriculum end up reenforcing each other.

\section{State-sanctioned gender roles}

This paper started out with the question: How does SNC, a state-sponsored curriculum, define the ideal gender roles for Pakistani society? In turn, what is the state ideology on gender and gender roles?

In asking this question, the research assumes that ideological power is exercised by state bodies through schooling and curriculum. As per Mann ${ }^{30}$, the requirement of meaning in social existence underpins ideological power. Those who have control over how others interpret social life have control over a source of power, which is usually the state (especially in non or quasi democracies). Norms and aesthetic practices are essential parts of social life, and those in charge of them wield power, e.g., religious bodies. Ideological power is wielded by and propagated through multiple institutions such as religion, mass media, or schooling. Hence, one can reverse engineer state ideology on gender through analysis of the statesponsored SNC.

Laursen $^{31}$ further emphasizes that curriculum, teaching methods, and disciplinary tactics are not only "practicalities" for transmitting the content of the instructional activity but are crucial to the socializing impacts of education. They are formed and founded on ideological preferences for order, reason, and purpose-directedness.

He further states that politicians, administrators, school leaders, and teachers are primarily concerned with the ideological question of legitimacy: "Does this type of school organization and practice appear reasonable to students, parents, and the general public, as well as in harmony with other societal organizations?" However, if the appeasement is being done of the oppressive norms of the society, movements for progressive social change are obliterated. In this case, the Single National Curriculum is an apologia for the patriarchal and misogynistic social organizations entrenched within Pakistan and Pakistanis.

\section{Conclusion}

The research found that the Single National Curriculum9 features heavily oppressive and misogynistic tendencies. With traditional gender roles firmly rooted through carefree omissions and sexist re-iterations, the SNC is a huge step backward for women empowerment and gender equality in Pakistan. The hidden curriculum of sexism is revealed through the analysis of the textbooks from grades 1-5. Students are taught to believe that the status gender norms of misogyny are the ideal conditions for family and public life. Since the SNC is introduced, promoted, and 
sponsored by the state, it goes to show the intentions of the state towards its female citizens. The patriarchal state remains, and the patriarchal society will persist if the SNC is to become the primary educational resource for the children of Pakistan.

\section{Acknowledgment}

I express my gratitude to my parents Asif and Shahida, siblings Tehreem and Bilal, best friend Ayesha, and my instructor Dr. Fatima Sajjad for supporting my personal and professional capabilities.

\section{References}

1. Durrani N. Schooling the 'other': the representation of gender and national identities in Pakistani curriculum texts. Compare. 2008;38(5):595-610.

2. UNESCO. Books, Gender Analysis of School Curriculum and Text. 2004.

3. Ullah $\mathrm{H}$, Skelton $\mathrm{C}$. Gender representation in the public sector schools textbooks of Pakistan. Educ Stud. 2013;39(2):183-194.

4. Kereszty O. Gender in Textbooks. In 2009. p. 1-7.

5. Peterson SB, Lach MA. Gender Stereotypes in Children's Books: their prevalence and influence on cognitive and affective development. Gend Educ. 1990;2(2):185-197.

6. Turner-Bowker D. Gender stereotyped descriptors in children's picture books: Does "curious Jane" exist in the literature? University of Rhode Island; 2020.

7. Treichler P, Frank F. Introduction: Scholarship, feminism, and language change. In: Language Gender and Professional Writing: Theoretical Approaches and Guidelines for Non-sexist Usage. NY; 1989. p. 1-32.

8. Chiponda A, Wassermann J. Women in history textbooks: what message does this send to the youth? Yesterday today. 2011;(6):13-25.

9. Single National Curriculum. Ministry of Federal Education and professional training [Internet]. Gov.pk. [cited 2021 Oct 15]. Available at: http://www.mofept.gov.pk/ProjectDetail/MzkyNDc 2MjMtY2VjYy00ZDA4LTk5OTUtNzUyNDI3ZWMzN 2Rm

10. Pakistan Institute of Development Economics. What really is the SNC? [Internet]. 2021. Available from: https://www.pide.org.pk/pdf/brief/What-really-isthe-Single-National-Curriculum-Webinar-Brief.pdf

11. Why a Single National Curriculum is Dangerous [Internet]. Thefridaytimes.com. 2020 [cited 2021 Aug $15]$.

Available

at: https://www.thefridaytimes.com/why-a-singlenational-curriculum-is-dangerous/

12. Zhang $Y$, Wildemuth BM. Qualitative analysis of content. In Applications of social research methods to questions in information and library science. Libraries Unlimited. 2009; 308-319.

13. Assor A, Gordon D. The implicit learning theory of hidden-curriculum research. J Curric Stud. 1987;19(4):329-339.

14. Saigol R. Knowledge and Identity: Articulation of Gender in Educational Discourse in Pakistan. ASR Publishers; 1995.

15. MOFEPT- Ministry of Federal Education and Professional Training. Social Studies. Single National Curriculum. Vols. 1-5. Punjab Curriculum \& Textbook Board; 2020.

16. MOFEPT- Ministry of Federal Education and Professional Training. General Science. Single National Curriculum. Vols. 4-5. Punjab Curriculum \& Textbook Board; 2020.

17. MOFEPT- Ministry of Federal Education and Professional Training. English. Single National Curriculum. Vols. 1-5. Punjab Curriculum \& Textbook Board; 2020.

18. MOFEPT- Ministry of Federal Education and Professional Training. Mathematics. Single National Curriculum. Vols. 1-5. Punjab Curriculum \& Textbook Board; 2020.

19. MOFEPT- Ministry of Federal Education and Professional Training. Urdu. Single National Curriculum. Vols. 1-5. Punjab Curriculum \& Textbook Board; 2020.

20. MOFEPT- Ministry of Federal Education and Professional Training. Islamic Studies. Single National Curriculum. Vols. 1-5. Punjab Curriculum \& Textbook Board; 2020.

21. Deutsche Welle (www. dw.com). Pakistan: How poverty and exploitation drive child marriages [Internet]. Www.dw.com. Deutsche Welle (www.dw.com); [cited 2021 Sep 1]. Available at: https://www.dw.com/en/pakistan-how-povertyand-exploitation-drive-child-marriages/a-56841723

22. The Qarawiyyin Project. Khadijah (ra): A standard working mother? [Internet]. Qarawiyyinproject.co. 2018 [cited 2021 Aug 15]. Available at: https://qarawiyyinproject.co/2018/03/16/khadijahra-a-standard-working-mother/comment-page-1/

23. Noori MH. Mustadrak al-Wasa'il wa Mustanbat alMasa'il. In: WikiShia. p. 48.

24. History of Bibi Fatima's Tasbih and its Practice Today [Internet]. The.ismaili. 2021 [cited 2021 Oct 15]. Available at: https://the.ismaili/usa/history-bibifatimas-tasbih-and-its-practice-today 
25. Bibi S, Ashfaq S, Shaikh F, Qureshi PMA. Prevalence instigating factors and help seeking behavior of physical domestic violence among married women of Hyderabad Sindh. Pak J Med Sci Q. 2014;30(1):122-125.

26. Mikkola M. feminist perspectives on sex and gender. In: Zalta EN, editor. The Stanford Encyclopedia of Philosophy. Fall 2019. Metaphysics Research Lab, Stanford University; 2019.

27. Simone de Beauvoir, Marso L, The Second Sex. Levy JT, editor. Oxford University Press; 2016.

28. Omission bias - biases \& heuristics [Internet]. Thedecisionlab.com. 2019 [cited 2021]. Available at: https://thedecisionlab.com/biases/omission-bias/

29. With Transgender Rights, Pakistan has an Opportunity to be a Pathbreaker [Internet]. Amnesty.org. 2019 [cited 2021 Aug 25]. Available at: https://www.amnesty.org/en/latest/news/2019/01/ with-transgender-rights-pakistan-has-anopportunity-to-be-a-path-breaker/

30. Mann M. The sources of social power. Cambridge University Press; 1986.

31. Laursen PF. Ideological power in education. Eur Educ Res J. 2006;5(3-4):276-284.

32. Blackstone AM. Gender Roles and Society. An Encyclopedia of Children, Families, Communities, and Environments. 2003;335-338. 